\title{
Animating Dance and Dancing with Animation: A Retrospective of Forever Falling Nowhere
}

\author{
Clare Brennan \\ Abertay University \\ Bell Street, Dundee, UK, DD1 1 HG \\ c.brennan@abertay.ac.uk
}

\author{
Lynn Parker \\ Abertay University \\ Bell Street, Dundee, UK, DD1 1HG \\ l.parker@abertay.ac.uk
}

\begin{abstract}
Experimental animation and contemporary dance share a number of concepts, including the abstraction of ideas and themes, seeking to communicate with an audience through movement, syncopation, shape, and rhythm. Within this paper the authors investigate communication through movement within these two forms, firstly through discussion of professional experimental animation and dance performances and secondly through specific analysis of the digital dance performance Forever Falling Nowhere. The paper documents discussion with the choreographer, dancer, animator and the audience, seeking to examine the connection between the concept of the piece, the use of movement to imply meaning from the point of view of each of the creators and the audiences' perception. The paper will conclude by reflecting upon the importance of interpretation within experimental works asking if Norman McLaren's definition of animation can be used to draw deeper meaning from digital performances.
\end{abstract}

\section{Experimental animation. Contemporary dance. Hybrid digital performance. Abstraction.}

\section{INTRODUCTION}

'What happens between each frame is more important than what happens on each frame' (McLaren [no date], cited in Solomon 1987, p.11). Norman McLaren's definition of animation is one of the most quoted insights into the animation process (Wells 2002, p.6) suggesting that his words resonate with the animation community. This definition is expanded by McLaren to state that 'animation is the art of manipulating the invisible interstices between frames' (cited in Solomon 1987 , p. 11) therefore, it is clear, that to McLaren it is not the individual creation of a frame of animation but more the decisions that are made between each frame or from frame to frame which 'more accurately defines the animator's art' (Wells 2002, p. 7). Within this paper, the space between the frames is observed closely, looking at the creative process undertaken in producing experimental works paying particular interest to the meaning suggested by manipulation and its product (movement) which is created within this space.

Erin Manning is a practicing artist in the fields of dance and interactive installation and is also a cultural theorist and philosopher. Manning (2012, p. 6) presents a definition of movement, which draws parallels with that of McLaren, she discusses preacceleration, 'the virtual force of movement's taking form' where a movement is felt in the body before it is actualised. Preacceleration is the creative potential of a movement before it becomes a movement influenced by external forces and physical limitations of the body. In this way, preacceleration is to physical movement as McLaren's definition of the space between the frames is to animation: Potential in the creative freedom of movement, and its actualisation within a film or performance. Preacceleration can be seen as the creative process of the dancer and animator whereas movement itself is the product; the dance or animation actualised within a space or upon a screen.

This paper discusses movement within experimental animation and dance with consideration of expression, emotion, and interpretation. Using the works of existing artists as a conceptual framework, the original performance Forever Falling Nowhere (2013) is examined from the perspectives of both the creators and the audience. 


\section{BACKGROUND}

The art creation process can be seen as a cycle; the artist has intent, the intent turns into a product and the product is viewed by an audience. Reflection upon the artwork by the artist may lead to further artistic intent and the cycle begins again. When working beyond representational form, the work of an artist, whether an abstract painting, a poem, an experimental animation or dance, requires some level of interpretation: Interpretation by the artist of their intent in making a work, and interpretation by the audience to engage with the work to make meaning of it for themselves (Furniss 2008). Experimental Animation and Dance share many parallels; they utilise time, movement and music to 'create narratives' (Wells 1998, p. 112) and often require interpretation to be understood by the audience. The art creation process for such works demonstrate further parallels, specifically in the intent of the artist, the work itself and its interpretation by an audience. These three stages of art creation will be analysed, through study of the Animators Norman McLaren and Oskar Fischinger and the choreographers Martha Graham and Isadora Duncan. These artists were selected for this study as there is a common theme throughout their practice of emotional expression. This emotional expression is of particular interest as it provides a foundation for discussion of the interpretation of the work.

\subsection{Artistic intent}

Fischinger, McLaren, Duncan and Graham share the wish to express emotion, through movement. McLaren sought to express his 'inner feelings', but not his 'inner thoughts and opinions' (McLaren 1971, cited in McWilliams 1991, P 38). He claims 'In Begone Dull Care, I'm telling them how I feel about that music; in A Chairy Tale how I feel about the chair being sat upon.' McLaren used film to convey his personal and automatic reaction to phenomenon whether it be an object, sound track or colour. The response motivates the work, which in turn informs his ideas about the work. Conversely, Duncan ((no date), cited in Daly 1995, p. 30) believes that dance is 'not only the art that gives expression to the human soul through movement, but also the foundation of a complete conception of life.' To Duncan, movement in dance communicates fundamental aspects of life and expresses the innermost thoughts and desires of the creators. This philosophy is somewhat shared by Oskar Fischinger.

Fischinger named many of his early animations sequentially, demonstrating his focus on development of skills and understanding. He saw these studies to be experiments to develop his grasp of technique until he perfected an approach to 'produce expressions which had to be brought into reality - and were somehow deep inside as subconscious desire, ideal or image existing from the beginning' (Fischinger 1949). Graham echoes this experimental approach claiming that 'Movement in modern dance is the product not of invention but of discovery - discovery of what the body will do' ((no date) cited in Freedman 1998, P 64). It becomes clear that experimentation through trial and error is central to the communication of these artists and in doing so, they can consciously or otherwise unlock meaning and expression in their work. Graham ((no date) cited in Freedman 1998, p. 56) believed 'If it could be said in words, it would be: but outside of words, outside of painting, outside of sculpture, inside the body is an interior landscape which is revealed in movement' and Fischinger (1949) supports this, extending his discussion of animation in particular to 'I want this work to fulfill [sic] the spiritual and emotional needs of our era. For there is something we all seek -something we try for during a lifetime working at filmmaking,...hoping despite all that, here and there, one day, perchance, something will be revealed, arising from the unknown, something that will reveal the True Creation: the Creative Truth!'

Clear artistic intent underpinned the creation of work, either seeking to express emotion through reactive (as McLaren) or experimental iterative practice (Graham and Fischinger). Their practice is evident within their creative outcomes and provides further insight into the modes of communication utilised to actualise their intent.

\subsection{Expression through motion and syncopation}

Motion of the body whether animated or physical is the primary mode of communication for these artists. Duncan and Graham share a preoccupation with nature in their choreography, Duncan rejected control (Daly 1995) whilst Graham relied on control of the breath and contrasting motion (Freedman 1998). Duncan's performances utilised free flowing gesture which often seemed improvised to her audiences (Daly 1995). Graham on the other hand believed that by mastering breath, the source of life, she "could convey heightened emotions. Intense feelings were revealed not simply by gestures of the hands and arms, but through powerful contractions and releases' (Freedman 1998). 'By focusing on the basic activities of the human form, she enlivened the body with raw, electric emotion' (Marthagraham.org 2012). McLaren also utilises contrast in his film Pas De Deux (1968) as the dancer of the piece interacts with a double of herself. The double holds poses on the screen which act as silhouettes to foreshadow the fluid movement of the dancer. The juxtaposition of 
stillness and movement and multiplicity of form communicate themes of frustration and separation (McLaren 1974, cited in McWilliams 1991, p. 41). Fischinger's film Optical Poem (1937) also focusses on the body, studying body and movement of 'the parts of a whole and the whole itself' (Bendazzi 1994, p. 124). This film utilises geometric forms to act as different parts of an orchestra. The motion is individual at first, but as the music and melody builds, implied relationships are created between the forms as they become connected through invisible ties unifying their movement whilst remaining individual.

Music and sound can play central role for the creation of these artists' work. Sound can lead and inspire the motion itself through syncopation (as discussed in Optical Poem) or sound can be created after the visuals or choreography to provide accents to the meaning of the work itself. Duncan was one of the first dancers to utilise concert music in conjunction with her dances (Acocella 2013) which motivated her use of figurative motion and in some cases narrative. Fischinger also utilised music in this way, believing that 'music is the concentrated form of the thought and emotion of composer' (Whitehall [no date], in Russett \& Starr 1988 , p. 60). In the field of dance, Graham was seen as a pioneer through collaboration with composers to produce bespoke music which enhanced the syncopation of her work (Freedman 1998). In Frontier (1935) the mix of fast staccato motions are underpinned by upbeat wind instruments, whilst a section where she seems to float across the floor, facing the audience throughout is supported by a high pitched string section which suggests defying gravity. McLaren shares this interest in syncopation, his 'style consists especially of rhythm and coherence (or even fusion) of the visual rhythm with the rhythm of sound' (Bendazzi 1994, p. 117).

Harmony between sound and motion is a central concern for these artists. Duncan aimed to fuse two 'sister arts' dance and music and the pioneering use of a symphony in Blue Danube (1902) inspired her interpretive powers and modes of expression (Duncan 1958, p. 9). In animation, Fischinger also sought for a link between visual rhythm and sound rhythm (Bendazzi 1994) as he believed 'the application of acoustical laws to optical expression was possible. As in the dance, new motions and rhythms sprang out of the music - and the rhythms became more and more important' (Fischinger 1947). Conversely, Graham's later work moves towards dance as an independent art which is particularly evident through the sparse soundscape and staccato choreography of Primitive Mysteries (1931) (Daye 2010). For McLaren, the connection was more intuitive as he 'used to see abstractions in his mind as he listened to music. With film, he realised he could make these abstractions visible' (McWilliams 2006).

\subsection{Audience interpretation}

Experimental or abstract works require the audience to 'read' or interpret the media in order to make meaning for themselves (Furniss 2008). Bendazzi (1994) believes that 'At first viewing, McLaren's work usually baffles the spectator. The exuberance of the unusual techniques, the absence of a 'meaning', the apparent coldness, are difficult elements for an audience used to other means of communication.' It is McLaren's avoidance of conventional narrative storytelling that leads to this confusion. Both McLaren and Fischinger rely upon movement, audio, and syncopation to communicate their message. McLaren believed that minimising visual elements which were not core to his message allowed more direct communication with his audience (McWilliams 1991). Abstraction was a tool to help him communicate but could also be read as alienating a section of his audience. Fischinger on the other hand believed in True Creation, and that 'The real artist should not care if he is understood, or misunderstood, by the masses. He should listen only to his Creative Spirit and satisfy his highest ideals, and trust that this will be the best service that he can render humanity' (Fischinger 1949).

Fischinger's work is appreciated by film historians and animation scholars, and in his home country of Germany and throughout Europe his early films were widely screened (Russett \& Starr 1988). Fischinger moved to America, to work with Warner Brothers and later with Disney. Both partnerships ended early due to disconnect between commercial animation expectations and Fischinger's ideals (Whitehall [no date], in Russett \& Starr 1988).

As Duncan was a pioneer of contemporary dance, her audience at first found her approach novel, many attending her performances to debate the need for visualisation of classical music (Duncan 1958). Her performances grew in popularity due to her ability to communicate her imagination through dance and her presence on stage, which left an impression upon her audience, even those who did not understand her art (Duncan 1958). For those who engaged with her work they saw her performances as an expression of their own internal thoughts and feelings (Daly 1995). Graham also evoked this feeling within her audience; she performed throughout times of political and social unrest and many saw her performances as a beacon for their desire for change because she ingrained 'the struggles of the individual' within her practice (Marthagraham.org 2012). Graham's work predominately relates to American life, and European audiences felt that 'she was 
'reenvisioning [sic] the very idea of dance claiming that her performances were indescribable and needed to be experienced in person (KorppiTommola 2010). In reflecting upon her own career Graham said 'I'm afraid that I used to hit audiences over the head with a sledgehammer because I was so determined that they see and feel what I was trying to do. Now I know...that you must draw people to you, like a magnet - perhaps by the intensity of your own belief' (Freedman 1998).

\section{HYBRID PERFORMANCES}

Animation is predominantly screen based media and although it shares a great deal with dance, it does not typically exist within or inhabit a three dimensional space in the same way as dance. Digital Performance is the term broadly used for physical performances which make use of digital media (Dixon 2007) and there are many examples of works which have tried to fuse these two worlds, recognising their strengths to create a new form of expression. Wells (2002, p. 6-7) claims that the potential reorientation [within animation] of the physical and material environment under these terms and conditions also re-configures the ways in which the psychological, emotional and physical terrain may be explored.' In a way, digital performance extends this definition of physicality, bringing animation into a performance space. There are many successful examples of digital performance including the digital dance works BIPED (1999) and Resonate (2013) and the theatre and dance performances of 4D Art including Icarus (2014) Anima (2002) and Beauty and the Beast (2011).

Digital performance, the fusing of the physical world and animated world extends both forms by allowing animation to inhabit a space and providing dance with methods to reframe performance.

Forever Falling Nowhere was a collaborative project involving experimental animation, projection, contemporary dance and musical composition which resulted in a site-specific live performance as part of NEoN Digital Arts Festival. The project was thematically inspired by Ray Bradbury's short story 'Kaleidoscope' and drew some aesthetic inspiration from the psychedelic visuals of the Kaleidoscope, invented by Scottish designer Sir David Brewster in 1816.

This performance was achieved through a mutual desire to collaborate in an authentic way, through a shared love of the narrative inspiration and a genuine curiosity and appreciation of each other's practice. It was an entirely inter-disciplinary process, however all collaborators brought their own individual sources of inspiration, motivation and interpretation; their own creative intent.

The piece was structured in a way which allowed the dancers and the projected animations to make both a physical and aesthetic journey. Set in an open industrial space the performance areas stretched throughout the room, creating a semipromenade staging style where the audience were encouraged to move through the space as the performance developed. There were five chapters of the performance which enabled the narrative to unfold as we tracked the dancers and the animations through each chapter. These can be defined as:

(i) Ambient movement within projected animations. Dancers walking, running and gliding throughout the space and amongst the audience. There is a droning soundscape which floats in the air, becoming heavier as the scene progresses.

(ii) The solo dancer begins to breathe slowly and deeply, contracting and releasing. An abstract animation of her breath grows to form her shadow. Multiple animated digital doubles appear and begin to defy gravity, breaking the monotony of the repetitive movement. The second dancer appears and they begin interact with their animated shadows, at first manipulating each other and then slowly breaking away.

(iii) The third chapter takes us to another area; a physical structure of large cubic shapes which have a series of projections building on them. It feels chaotic and dangerous. As the scene progresses the dancers begin to work in tandem, supporting and controlling each other's bodies. Soon they are in tune and a sense of control is discovered.

(iv) The atmosphere changes as the tempo of the music slows. The focus shifts again to another area of the space. There is a sense of the beginning of something new, of peace and serenity born out of chaos.

(v) The fifth chapter connects all three performance spaces as the dancers are separated, moving to either side of the space. The mood is one of reflection, each dancer interacting with filmic version of their memories where they reflect, in isolation until they meet their end. 


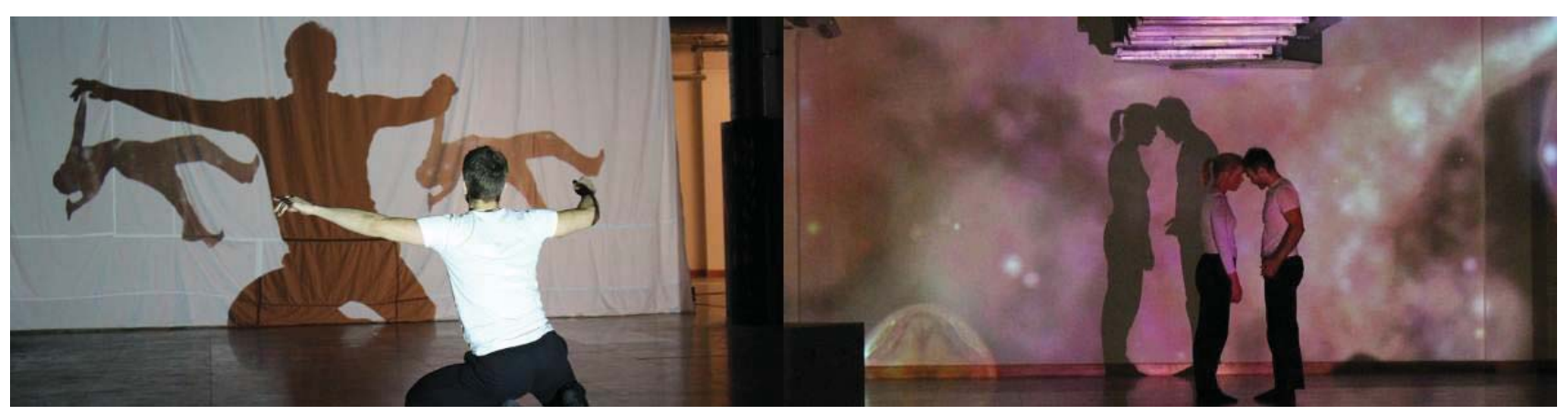

Figure 1: Photographs from the performance Forever Falling Nowhere (2013). On the left is an image of the dancer interacting with the digital doubles in Chapter two and on the right is a tender moment from chapter four. Images courtesy of Robyn Mayer, 2013

\subsection{Study design}

To gather information regarding audience experience and interpretation, and to gain insight in to the co-collaborator's experience, development process, creative intent and personal meaning, we developed two questionnaires; one directed at the audience and one designed for the cocollaborators. We selected a small but diverse cross-section of audience: two males and 4 females, aged 20-42 which reflected the ratio and diversity within our audience. The co-collaborator questionnaire was completed by the Choreographer, the Animator, the Visual Effects designer, the Musician and the Festival and Events Curator. The results from these questionnaires will be used to analyse the performance.

\subsection{Viewpoints and interpretation: results}

\subsubsection{The co-creators responses}

In the early stages of the creative process there were clear shared visions for the thematic journey of the piece. Initial conversations and early iterations of creative material, be it dance, animation or music, were created with the desire to evoke feelings of love and death, recalling memories of relationships, and to depict moments of isolation and space. As the journey of creating the performance developed there were a number of key points where these themes, and the individual interpretation of these themes began to expand and evolve. Within each chapter we reached deeper in to the story. The dancers began to play with the animations, to play with the space, to explore physical limitations and to feel, understand and interpret the narrative.

When asked to identify the themes of the project, the collaborators interpretations varied greatly. The spirit of the words used was in keeping with the original concept of the piece, but it is clear that each of the collaborators had moved beyond the initial concept to make something new for themselves. Death and love were the most commonly cited themes (three citations each) followed by reflection, isolation, relationships and morality (2 citations each). There were 16 additional words used to describe the themes of the project which had only one citation each. These included: Serenity, longing and morality

The results suggest that extended periods of play and experimentation within the development process produced the most memorable results for the co-creators. The data reveals specific moments when all collaborators were in tune with their interpretations of the themes and when their creative intent was shared. The results also identify moments where the creative intent and interpretation was in conflict. The limitation in terms of experimentation in the development phase may be a factor.

In an early part of the performance the Choreographer and Animator seem to be striving for contrasting effects; the animator talks of communicating a 'desolate emptiness', whilst the choreographer was trying to 'create chaos.' However as the development of the performance progressed the collaborators ambitions converged. In chapter two the choreographer and animator wished to achieve a sense of weightlessness, exploring bodies in suspension. The animator designed the visuals to support and amplify the dancer's sense of weightlessness, creating another dimension to achieve the sense of defying gravity. It was felt that this helped to convey the notion of new life and the routine of everyday life. The animator then introduced a change in the colour palette with the intention of representing a freedom from routine and monotony which aligned with the choreographer's effort to build an energy and intensity. The musician sought to support the initial sense of repetition and then as the scene progresses the music evolves to find an obscure rhythm to build energy and momentum.

The results suggest that the collaborators begin to feel more in tune with each other as the chapters of the performance progress. The animator talks of creating an ambience which is 'slow, thoughtful and 
reflective', which mirrors the choreographer's intention to show the body breaking down reflecting upon 'a life that they may have lived before' until 'the body returns to dust'. The animator utilised soft shapes which move slowly through space building the intensity of colour to show that although life is a cycle, the world is richer from this journey. When creating these visuals the animator commented that 'the music became a motivating force for the animations and the objects within them' and noted that it 'enhanced the connection between the visuals and the dancers' movements as the sound tied these together'. The musician drew inspiration from film soundtracks, utilising analogue technology to harness a vintage sound evoking nostalgia and romanticism of memory.

The collaborators identified having the greatest personal connection to chapters four and five. Chapter four drew attention to personal relationships of two of the collaborator, causing them to reflect individually own their own experiences of relationships. Chapter five, evoked reflection upon memories and childhood. One collaborator identified regret in amongst their experience. Three of the collaborators made little reference to their own personal connections to the performance. Two collaborators instead focussed on the development of technique or skills

\subsubsection{The audiences' responses}

A cross-section of the audience were given the opportunity to feedback on their experience of the performance through the questionnaire. When discussing the themes in the broadest sense there was a general agreement from the audience members that 'connectivity' was the main theme (five citations). Audience members also identified love (three citations), relationships, separation and support or reliance as underpinning themes (two citations each). There were a further 13 themes presented with only one citation each. These themes varied widely from body image to the vastness of the universe.

As the respondents elaborated on these themes they spoke of moments when they interpreted the movement as metaphors for connectivity, support and reliance. One audience member recalls that the movement of the dancers demonstrated a shift from effort to fluidity as they 'were starting to work together and depend on each other, it wasn't a smooth transition but by the end they were working in tandem.' Another respondent elaborates on the ways in which the dancers and animation worked together to enhance the theme of connectivity by saying, 'They built upon each other and it felt seamless. The dancers' movements seemed like a part of the animation in the projection. Also I felt like the dancers gained a story and character throughout the performance, they were telling a story not just moving through a space.'

However, when discussing the finer details of their interpretation of narrative it was revealed that they reflected their own life experience upon the story. As individuals they began to identify their own memories and so the perception of the narrative differed greatly from person to person.

One respondent said that they 'loved the part where the dancers seemed to be travelling in space. People looking out at the universe, so large and awesome is always really evocative and moving to me. Quite magical.' Whereas another interpreted the whole performance to relate to 'the idea of being able to see something beautiful in something tragic - through memories and experiences.' In contrast, one respondent suggested that the creators of the visuals 'were thinking strongly about pregnancy, or the act of biological creation' and another participant recognised the subjectivity of the experience stating that 'if I was to re-watch it again there would be different parts and had my life story been different there would be other parts and that's the part, you know, any good art is a mirror in a strange way. It didn't force me to feel anything, it let me feel something.'

When asked about the most memorable element of the performance, in terms of modality (animations, dance, music) six of the respondents commented upon the connection between the music, movement and projections, stating that no single element stood out but rather they worked together to create a total experience.

\section{DISSCUSSION AND CONCLUSION}

The results from this study demonstrate the breadth of interpretation of artwork from both the perspectives of the creator and the audience. Within the creative team, intent varied from artistic communication to development of technique. From the discussion of McLaren and Fischinger, it is clear that technique must often be refined before concept is applied. The different priorities within our creative team support this philosophy and also demonstrate the diversity of the creative process. The development of the performance required collaboration between diverse disciplines and the development of a shared language. The projects strengths are in the iteration of this aspect, in the considered and sensitive development of individual elements in relation to the performance as a whole. The approach to movement within animation and dance was heavily underpinned by bespoke music, which was iteratively developed as the themes of the project evolved. Like Graham, the team relied 
on music to guide physicality of the action and like Fischinger, we hoped to created harmony between the visuals and music.

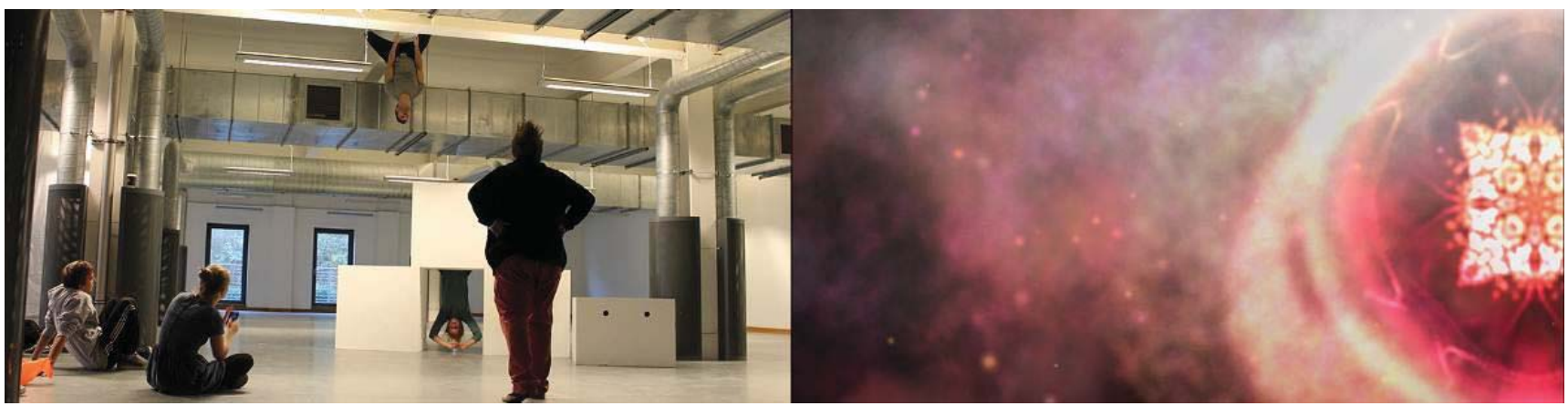

Figure 2: Forever Falling Nowhere (2013) fused interdisciplinary practices of dance, animation and music to create a total experience. The image on the left is the collaboration in process and on the right is a still image from the animation for chapter four. Images courtesy of Lynn Parker, 2013

The audience as a whole identified broadly similar themes, highlighting key elements such as connectivity, love, relationships, separation, support and reliance. These differ slightly from the intention of the creative team; however the themes of love, and relationships were interpreted by the audience. The universal nature of these two themes may have aided their communication as audience members apply their own values and experiences to their interpretation of the experimental aspects of the performance. The audience results further support this idea as many of the respondents reported an emotional connection to the fourth chapter in particular, which was the most abstract of the performance.

The chapters of the performance where the animator and choreographer clearly maintained a shared vision were very positively received by the audience, and allowed the audience to create their own meaning within the spirit of the work. Where there was a slight difference in vision, the audience responded less positively or failed to comment.

In discussing the work of Fischinger, McLaren, Graham and Duncan, it has become clear that expression through movement can be achieved in countless ways. These four artists are responsible for a wealth of experimentation with movement, music and expression and are a small sample of practitioners within their fields. Experimental animation draws a great deal from contemporary dance and dance can and is learning from animation through augmentation of space and the body in digital performances. This short study of digital performance and the work of these four practitioners demonstrates potential for both technical and expressive development through further interdisciplinary collaboration. The analysis of Forever Falling Nowhere echoes this sentiment as the audience considered the performance as a total experience rather than focussing upon one distinct art form within the piece.
This study utilises a small number of audience respondents to what was a well-attended event (200+ people). This cross-section is representative of the age, gender and background of attendees so provides some small insights into the impact of the performance. To fully corroborate the findings of this paper this study should be extended to a larger sample.

In reference to McLaren's definition that animation is what happens between the frames, this research suggests that the collaborative interdisciplinary nature of digital performance pushes the boundaries of what is possible in movement and expression. It is this interaction, this discussion and iteration in-between the making of movement which strengthens expression and meaning.

\section{REFERENCES}

Acocella, J. (2013) A Very Late Romantic: Isadora Duncan. Available from: http://www.nottinghilleditions.com/uploads/essaywi nners/NHEessayACOCELLA.pdf (retrieved 19 March 2014).

Bendazzi, G. (1994) Cartoons: One Hundred Years of Cinema Animation. Indiana University Press: Indianapolis.

Daly, A. (1995). Done into Dance: Isadora Duncan in America. Wesleyan University Press :Middletown

Daye, A. (2010) Keeping Alive the Wonder: Primitive Mysteries, New York 1931 to London 2009. Dance Chronicle 33(1): . Available from: http://www.tandfonline.com.libproxy.abertay.ac.uk/d oi/full/10.1080/01472520903574790\#tabModule (retrieved 20 March 2014).

Dixon, S. (2007) Digital Performance. MIT Press: Cambridge. 
Duncan, I. (no date) Cited in Daly, A. (1995) Done into Dance: Isadora Duncan in America. Wesleyan University Press: Middletown.

Duncan, I. (1958) Isadora Duncan: Pioneer in the Art of Dance. New York Public Library. Available from:

http://babel.hathitrust.org/cgi/pt?id=uc1.321060007 82836;view=1up;seq=4 (retrieved 19 March 2014).

Fischinger, O. (1947) My Statements are in My Work Available from: http://www.oskarfischinger.org/MyStatements.htm (retrieved 16 March 2014).

Fischinger, O. (1949) True creation. Available from: http://www.oskarfischinger.org/True\%20Creation.ht $\mathrm{ml}$ (retrieved 19th March 2014).

Freedman, R. (1998) Martha Graham: A Dancer's Life. Clarion Books: New York.

Furniss, M. (2008) Art in Motion: Animation Aesthetics. Rev. ed. John Libbey: New Barnet.

Graham, M. (no date) Cited in Freedman, R. (1998) Martha Graham: A Dancer's Life. Clarion Books: New York.

Korppi-Tommola, R. (2010) Politics Promote Dance: Martha Graham in Finland, 1962. Dance Chronicle 33(1): Available from: http://www.tandfonline.com.libproxy.abertay.ac.uk/d oi/full/10.1080/01472520903574766\#.Uyt6uvl_sp8 (retrieved 20 March 2014).

Manning, E. (2012) Relationscapes: Movement, Art, Philosophy. The MIT Press: Cambridge.

Marthagraham.org. (2012) History. Available from: http://marthagraham.org/about-us/our-history/ (retrieved 19 March 2014).
McLaren, N. (no date) Cited in Solomon, C. (1987). Animation: Notes on a Definition. In Solomon, C. (eds). The Art of the Animated Image: An Anthology. The American Film Institute: Los Angles.

McLaren, N. (1971) Cited in McWilliams, D. (1991). Norman McLaren: On Creative Process. Available from: http://onf-nfb.gc.ca/sg/100122.pdf (retrieved 19 March 2014).

McLaren, N. (1974), cited in McWilliams, D. (1991) Norman McLaren: On Creative Process. Available from: http://onf-nfb.gc.ca/sg/100122.pdf (retrieved 19 March 2014).

McWilliams, D. (2006) Norman McLaren Biography Available from: http://www3.nfb.ca/animation/objanim/en/filmmaker s/Norman-McLaren/biography.php (retrieved 19 March 2014).

McWilliams, D. (1991) Norman McLaren: On Creative Process. Available from: http://onfnfb.gc.ca/sg/100122.pdf [retrieved 19 March 2014]

Russett, R., Starr, C. (1988) Experimental Animation: Origins of a New Art. Rev. ed. De Capo Press: New York.

Wells, P. (1998) Understanding Animation. Routledge: London.

Wells, P. (2002) Animation: Genre and Authorship. Wallflower: London.

Whitehall, R. (no date) Bildmusk - Art of Oskar Fischinger in Russett, R., Starr, C. (1988) Experimental Animation: Origins of a New Art. De Capo Press: New York. 